\title{
Prediksi Kebutuhan Tempat Tidur Menggunakan Metode Data Mining
}

\section{Prediction of Available Beds using Data Mining Method}

\author{
Dwi Indah Puspitasari ${ }^{1}$, Edi Jaya Kusuma ${ }^{1, *}$, Kriswiharsi Kun Saptorini ${ }^{1}$, Evina Widianawati ${ }^{1}$ \\ ${ }^{1}$ Program Studi Rekam Medis dan Informasi Kesehatan, Fakultas Kesehatan, \\ Universitas Dian Nuswantoro, Semarang \\ Jl. Imam Bonjol No.207, Pendrikan Kidul, Semarang Tengah, Kota Semarang 50131, Indonesia, \\ *e-mail korespondensi: edi.jaya.kusuma@dsn.dinus.ac.id
}

\begin{abstract}
Abstrak
Dalam studi kasus yang dilakukan di bangsal Umar di Rumah Sakit Islam (RSI) Kendal, Jawa Tengah, diketahui bahwa pada tahun 2020 bangsal tersebut memiliki 22 tempat tidur. Berdasarkan data statistik yang diperoleh, nilai indikator Barber-Johnson yang ada pada bangsal Umar masingmasing adalah BOR 65.2\%; LOS 2.85; TOI 1.52; dan BTO 83.68. berdasarkan indikator tersebut efisiensi penggunaan tempat tidur di bangsal Umar di RSI Kendal masih belum tercapai. Maka dari itu, agar mutu pelayanan kesehatan khususnya dalam hal efisiensi penggunaan tempat tidur pada bangsal Umar di RSI Kendal tercapai, penelitian ini mengimplementasikan metode data mining random forest untuk melakukan prediksi jumlah tempat tidur sesuai dengan standar Barber Johnson untuk tahun 2021 hingga 2023. Dari hasil pengolahan data didapatkan jumlah tempat tidur untuk tahun 2021 hingga 2023 pada bangsal Umar diprediksi memiliki 20 hingga 22 tempat tidur. Evaluasi terhadap tingkat efisiensi penggunaan tempat tidur di bangsal Umar dilakukan dengan memanfaatkan grafik Barber-Johnson. Dari grafik yang dihasilkan, dapat disimpulkan bahwa hasil prediksi jumlah tempat tidur mampu mencapai tingkat efisien. Hal ini disebabkan karena pada grafik Barber-Johnson bangsal Umar untuk tahun 2021 hingga 2023 titik pertemuan indikator tepat berada di daerah efisien.
\end{abstract}

Kata kunci: barber-johnson, data mining, efisiensi, random forest

\begin{abstract}
In a case study conducted in the Umar Ward at the Islamic Hospital (RSI) Kendal, Central Java, it was found that in 2020 the ward had 22 beds. Based on the statistical data obtained, the Barber-Johnson indicator values in Umar's ward were BOR 65.2\%; LOS 2.85; TOI 1.52; and BTO 83.68, respectively. Based on these indicators, the efficiency of the use of beds in the Umar Ward at RSI Kendal has not been achieved. Therefore, in order to achieve the quality of health services, especially in terms of efficient use of beds in the Umar Ward at RSI Kendal, this study implemented the random forest method to predict the number of beds according to Barber Johnson standards for 2021 to 2023. From the results of the study, the Umar Ward was predicted to have 20 to 22 beds for 2021 to 2023. Evaluation of the efficiency level of bed occupany in Bangsal Umar is carried out using the BarberJohnson chart. Based on the Barber-Johnson graph, it can be concluded that the prediction results of the number of beds are able to reach an efficient level. This is because on the Barber-Johnson chart of Umar Ward for the years 2021 to 2023 the intersection point of the indicator right in the efficient area.
\end{abstract}

Keywords: barber-johnson, data mining, efficiency, random forest

\section{PENDAHULUAN}

Rumah sakit merupakan salah satu institusi penyedia layanan kesehatan seperti unit rawat inap, uni rawat jalan, dan layanan gawat darurat sesuai dengan PERMENKES RI No. 340/MenKes/Per/III/2010 (Diwani \& Fahmi, 2020). Dalam proses pelayanan kesehatan oleh rumah sakit akan dihasilkan suatu data dari hasil pencatatan dan pengumpulan data. Hasil pencatatan dan pengumpulan data tersebut terlampir dalam dokumen rekam medis. Sesuai dengan PERMENKES RI No. 269/MenKes/Per/III/2008 (Diwani \& Fahmi, 2020), data rekam medis memiliki peran penting dalam penyediaan data yang selanjutnya 
dapat diolah guna menghasilkan informasi dalam bentuk laporan statisik rumah sakit.

Laporan statistik rumah sakit yang baik dapat digunakan sebagai salah satu acuan dalam upaya peningkatan mutu atau kualitas dari pelayanan rumah sakit (Silvana, Akbar, \& others, 2017) (Limirang \& Bachtiar, 2021). Selain itu, hasil dari laporan statistik rumah sakit juga dapat digunakan sebagai referensi penentukan maupun pembuatan kebijakan baru oleh pihak rumah sakit.

Salah satu unit yang memiliki peran besar dalam penentuan kualitas penyelenggaraan pelayanan rumah sakit adalah unit rawat inap. Unit rawat inap (URI) merupakan salah satu bagian rumah sakit yang memiliki tujuan kuratif dan rehabilitatif (Nugraheni \& Ruslinawati, 2016). Pada unit ini disediakan tempat inap berupa tempat tidur bagi pasien yang memerlukan observasi, diagnosis, terapi dan rehabilitasi lebih lanjut. URI merupakan salah satu komponen rumah sakit yang penting, karena pendapatan atau pemasukkan rumah sakit sebagian besar ditentukan oleh unit ini (Anisah, 2021). Oleh karena itu, rumah sakit sangat perlu melakukan evaluasi pengelolaan unit rawat inap tiap tahunnya, guna memberikan layanan URI yang baik kepada pasien.

Salah satu indikator evaluasi dalam URI adalah kapasitas tempat tidur. Selain jumlah tempat tidur yang tersedia dalam suatu bangsal di rumah sakit, efisiensi penggunaan tempat tidur juga menjadi acuan evaluasi. Penentuan tingkat efisiensi penggunaan tempat tidur dapat dilihat dari hasil grafik Barber-Johnson (Defiyanti, Setiatin, \& Susanto, 2021). Metode grafik Barber-Johnson dapat digunakan untuk membandingkan efisiensi penggunaan tempat tidur antar bangsal satu dengan lainnya di suatu rumah sakit (Nisa Srimayarti, Leonard, \& Zhuhriano Yasli, 2021). Terdapat empat parameter yang digunakan dalam proses konstruksi grafik Barber-Johnson, yaitu Bed Occupancy Rate (BOR), Average Length of Stay (AvLOS), Bed Turn Over (BTO), dan Turn Over Interval (TOI). Adapun nilai ideal untuk masing-masing indikator: BOR > 75\%, TOI antara 1 - 3 hari, LOS antara 3 - 12 hari, dan BTO minimal 30 kali (Utami, Azizah, \& Setiatin, 2021).

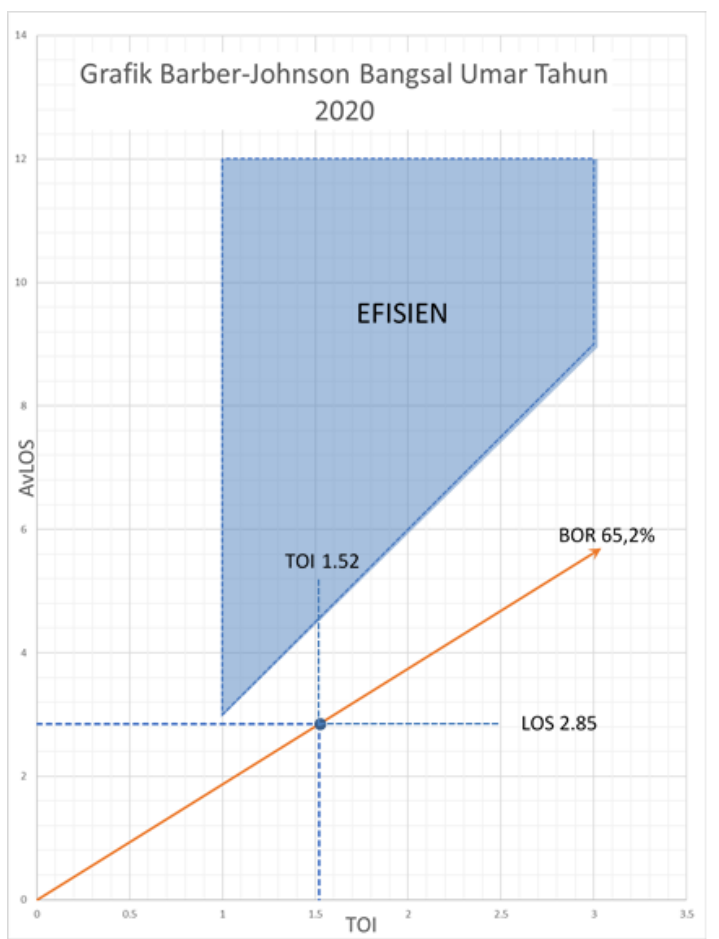

Gambar 1. Grafik Barber-Johnson Bangsal Umar Tahun 2020

Dalam studi kasus yang dilakukan di bangsal Umar di Rumah Sakit Islam (RSI) Kendal, Jawa Tengah dapat diketahui bahwa pada tahun 2020 bangsal tersebut memiliki sebanyak 22 tempat tidur. Kemudian berdasarkan data statistik yang diperoleh, nilai indikator Barber-Johnson yang ada pada bangsal 
Umar masing-masing adalah BOR 65.2\%; LOS 2.85; TOI 1.52; dan BTO 83.68.

Dari indikator-indikator tersebut dapat dihasilkan grafik Barber-Johnson pada gambar 1. Dari grafik tersebut dapat diketahui bahwa titik potong beberapa indikator masih jatuh di luar daerah efisien. Hal ini menunjukkan bahwa pada tahun 2020, efisiensi penggunaan tempat tidur di bangsal Umar di RSI Kendal masih belum tercapai.

Agar tercapainya mutu pelayanan kesehatan khususnya dalam hal efisiensi penggunaan tempat tidur pada bangsal Umar di RSI Kendal, penelitian ini akan implementasikan metode data mining random forest untuk melakukan prediksi jumlah tempat tidur sesuai dengan standar Barber Johnson untuk tahun 2021 hingga 2023. Dengan adanya prediksi jumlah tempat tidur ini, diharapkan dapat menjadi referensi dalam penentuan kebijakan terkait dengan capaian mutu pelayanan kesehatan di RSI Kendal.

\section{METODE PENELITIAN}

Penelitian ini menggunakan metode deskriptif dangan pendekatan retrospektif. Sumber data yang digunakan dalam penelitian ini adalah hasil rekapitulasi pada URI dari RSI Kendal pada periode tahun 2015 hingga 2020. Berdasarkan data tersebut akan dilakukan prediksi dengan menggunakan metode data mining random forest dengan memanfaatkan aplikasi Rapid Miner. Dari hasil prediksi tersebut kemudian diolah menggunakan analisa statistik Barber-Johnson untuk menemukan jumlah tempat tidur efisien.

\section{INDIKATOR BARBER-JOHNSON}

Indikator Barber Johnson merupakan indikator penilaian yang digunakan dalam pemantauan efisiensi pemakaian tempat tidur pada suatu fasilitias URI (Herawaty, 2021). Pada dasarnya terdapat empat indikator utama yang digunakan sebagai acuan penilaian yaitu Bed Occupation Rate (BOR), Average Length of Stay (AvLOS), Bed Turn Over (BTO), dan Turn Over Interval (TOI) (Seha, Nugroho, \& Harno, 2021). BOR merupakan persentase penggunaan TT dalam periode waktu tertentu (Fahrudin, 2021). AvLOS merupakan rata-rata jumlah hari atau lama waktu pasien yang menginap di rumah sakit. Kemudian BTO adalah nilai rata-rata jumlah pasien yang menggunakan tiap tempat tidur dalam kurun waktu tertentu. Sementara, TOI adalah durasi waktu suatu tempat tidur ketika tidak digunakan (Sidiq \& Afrina, 2017).

Masing-masing indikator memanfaatkan data rekapitulasi berupa data jumlah hari perawatan $(H P)$, jumlah pasien keluar hidup dan mati $(D)$, serta jumlah tempat tidur yang tersedia (A) (PRISUSANTI \& EFENDI, 2021). Untuk dapat menghitung masing-masing indikator digunakan persamaan dibawah ini (Diwani \& Fahmi, 2020):

$$
\begin{aligned}
& B O R=\frac{O}{A} \times 100 \% ; O=\frac{H P}{T} \\
& L O S=\frac{H P}{D} \\
& B T O=\frac{D}{A} \\
& T O I=(A-O) \times \frac{T}{D}
\end{aligned}
$$

Pada persamaan diatas konstanta $T$ merupakan jumlah hari dalam satu tahun yaitu 365 hari. Berdasarkan hasil perhitungan masingmasing indikator menggunakan persamaan diatas, Grafik barber johnson dapat dibuat untuk menggambarkan tingkat efisiensi suatu bangsal. Penentuan tingkat efisiensi bangsal dapat diketahui dari posisi pertemuan masing-masing indikator apakah berada di daerah efisien atau tidak.

\section{RANDOM FOREST}

Random Forest (RF) merupakan salah satu metode data mining yang sering digunakan untuk melakukan predikasi berdasarkan masalah regresi dan klasifikasi (Li et al., 2021). Metode Random Forest terdiri dari beberapa kombinasi pohon keputusan yang dilatih menggunakan himpunan data berlabelkan nilai tertentu (training set) (Ruyssinck et al., 2016). Setelah proses pelatihan model RF menggunakan data latih (training set), hasil keluaran akan digunakan untuk memprediksi nilai yang nilai labelnya belum diketahui.

\section{SUMBER DATA}

Pada penelitian ini memanfaatkan data yang di dapatkan dari hasil studi kasus pada bangsal Umar di RSI Kendal, Jawa Tengah. Adapun variabel yang digunakan dalam 
penelitian ini antara lain kapasitas tempat tidur, hari perawatan, jumlah pasien keluar hidup dan mati. Data tersebut dapat dilihat pada Tabel 1 dibawah ini.

Tabel 1. Data Rekapitulasi URI Bangsal Umar

\begin{tabular}{cccc}
\hline Tahun & $\begin{array}{l}\text { Kapasitas } \\
\text { TT }\end{array}$ & Jumlah HP & $\begin{array}{c}\text { Jumlah Pasien } \\
\text { Keluar (H+M) }\end{array}$ \\
\hline 2015 & 22 & 6426 & 1823 \\
2016 & 22 & 6060 & 1708 \\
2017 & 22 & 6361 & 1511 \\
2018 & 22 & 5894 & 1693 \\
2019 & 22 & 6324 & 2168 \\
2020 & 22 & 5250 & 1841 \\
\hline
\end{tabular}

Pada tabel diatas dapat diketahui bahwa dari tahun 2015 hingga 2020 belum ada pengurangan maupun penambahan jumlah tempat tidur di bangsal Umar. Data tersebut selanjutnya akan digunakan sebagai referensi dalam proses prediksi menggunakan metode random forest pada aplikasi Rapid Miner.

\section{HASIL DAN PEMBAHASAN}

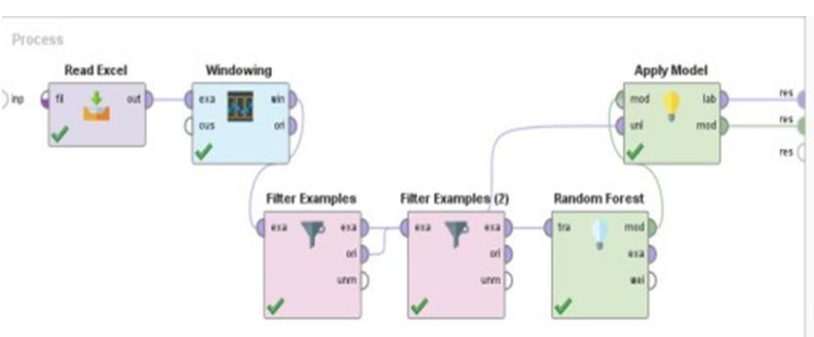

Gambar 2. Desain Model Prediksi Random Forest pada Aplikasi Rapid Miner

Pada gambar 2 dapat dilihat pada model yang dibuat menggunakan aplikasi Rapid Miner, terdapat operator windowing dimana operator tersebut berguna untuk memberikan perpanjangan data sehingga antar datanya memiliki relasi. Dari proses tersebut akan dihasilkan nilai prediksi dari variabel jumlah hari perawatan, dan jumlah pasien keluar hidup dan mati seperti yang ada pada Tabel 2 dibawah ini:

Tabel 2. Hasil Prediksi menggunakan Random Forest

\begin{tabular}{lll}
\hline \multirow{3}{*}{ Tahun } & \multicolumn{3}{c}{ Hasil Prediksi } \\
\cline { 2 - 3 } & Hari Perawatan & $\begin{array}{l}\text { Pasien Keluar } \\
\text { dan Mati }\end{array}$ \\
\hline
\end{tabular}

\begin{tabular}{lll}
\hline 2021 & 6085 & 1928 \\
2022 & 5477 & 1835 \\
2023 & 6051 & 1817 \\
\hline
\end{tabular}

Dari hasil prediksi Hari Perawatan (HP) pada bangsal Umar, RSI Kendal Jawa Tengah untuk tahun 2021 sampai 2023 di prediksi mengalami kenaikan dan penurunan. Bangsal Umar di perkirakan akan mengalami penurunan pada tahun 2022 sebesar 608 hari dari yang sebelumnya 6085 hari menjadi 5477 hari dan di prediksi akan mengalami kenaikan pada tahun 2023 sebesar 549 hari dari yang sebelumnya 5477 hari menjadi 6051 hari. Kemudian dari hasil prediksi jumlah pasien keluar hidup dan mati, bangsal Umar untuk tahun 2021 hingga 2023 diprediksi akan mengalami penurunan pasien disetiap tahunnya seperti tahun 2022 mengalami penurunan sebanyak 93 pasien dari 1928 pasien menjadi 1835 pasien, dan ditahun 2023 mengalami penurunan juga sebanyak 18 pasien dari 1835 pasien menjadi 1817 pasien.

Setelah hasil prediksi dari jumlah Hari Perawatan dan jumlah Pasien Keluar hidup dan mati pada bangsal Umar untuk tahun 2021-2023 didapatkan, maka tahapan berikutnya adalah menghitung prediksi jumlah kebutuhan tempat tidur pada bangsal Umar tahun 2021-2023 dengan menggunakan standar Barber Johnson dengan perhitungan $\mathrm{TOI}=1$, $\mathrm{TOI}=3$ dan $\mathrm{BOR}$ $75 \%$, untuk perhitungan prediksi jumlah kebutuhan tempat tidur tidak langsung diimplementasikan menggunakan teknik data mining. Hal ini dikarenakan adanya rumus khusus untuk perhitungan jumlah tempat tidur berdasarkan standar Barber-Johnson yang tidak dapat dimasukan ke dalam data mining.

Dari perhitungan prediksi didapatkan kebutuhan tempat tidur (TT) di bangsal Umar untuk tahun 2021 menurut standar Barber Johnson menggunakan asumsi nilai BOR $75 \%$ serta TOI 1 sampai 3 hari di ketahui kebutuhan tempat tidur dibangsal Umar tahun 2021-2023 antara 20 hingga 22 tempat tidur.

Tabel 3. Prediksi Jumlah TT berdasarkan standar BJ

\begin{tabular}{cccc}
\hline TT semula & $\begin{array}{c}\text { TT tahun } \\
2021\end{array}$ & $\begin{array}{c}\text { TT tahun } \\
2022\end{array}$ & $\begin{array}{c}\text { TT tahun } \\
2023\end{array}$ \\
\hline 22 & 22 & 20 & 22 \\
\hline
\end{tabular}

Dari hasil perhitungan prediksi Kebutuhan Tempat Tidur pada Tabel 3 untuk bangsal Umar menggunakan standar Barber Johnson menurut 
indikator BOR 75\% didapatkan hasil 22 tempat tidur. Sementara untuk mengetahui efisiensi dari penggunaan tempat tidur pada bangsal Umar untuk tahun 2021 perlu digambarkan grafik Barber-Johnson dengan mengombinasikan nilai statistik LOS $=6085 / 1928=3.16$ Hari, serta TOI $=(22-16.67) \times 365 / 1928=1$.

Pada Gambar 3 dapat dilihat bahwa hasil grafik Barber-Johnson bangsal Umar untuk tahun 2021 titik potongnya jatuh di area efisien. Sehingga dapat dikatakan bahwa pengelolaan bangsal pada bangsal Umar untuk tahun 2021 telah mencapai efisien sesuai dengan standar Barber-Johnson.

Kemudian hasil pada tahun 2022, berdasarkan perhitungan standar Barberjohnson, bangsal Umar diprediksi memiliki 20 tempat tidur. Lalu dengan menerapkan kembali hasil prediksi jumlah tempat tidur dengan statistik Barber-Johnson, didapatkan beberapa indikator yang dapat digunakan untuk menyusun grafik Barber-Johnson, yaitu LOS $=5477 / 1835$ $=3$ hari, dan $\mathrm{TOI}=(20-15.1) \times 365 / 1835=1$ hari.

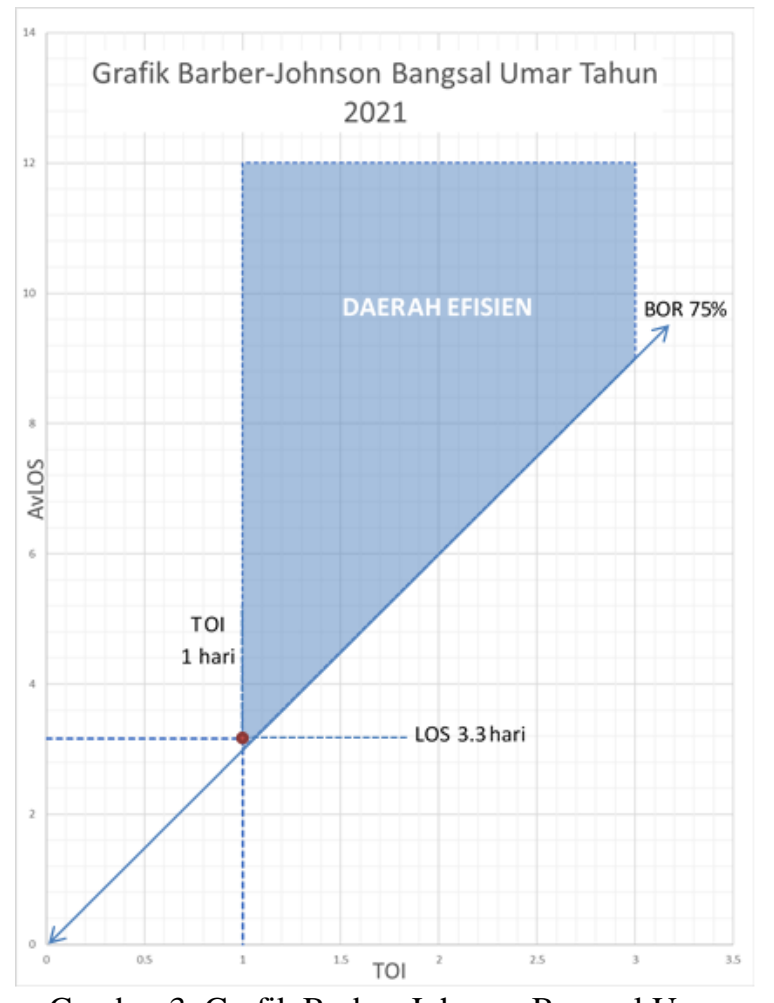

Gambar 3. Grafik Barber-Johnson Bangsal Umar pada Tahun 2021

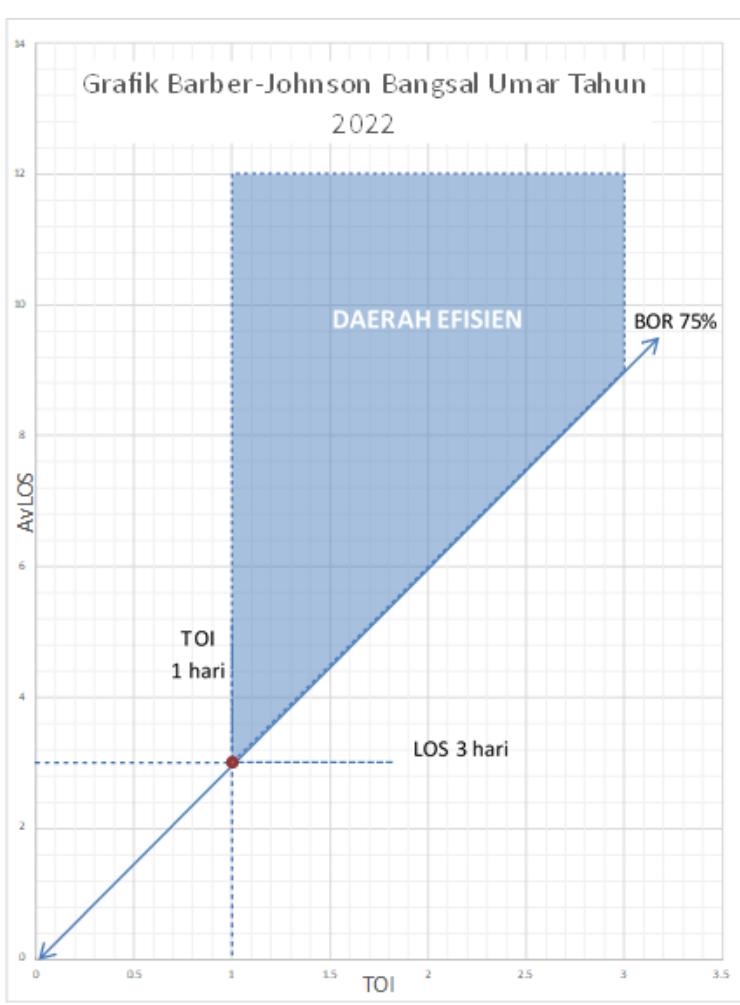

Gambar 4. Grafik Barber-Johnson Bangsal Umar pada Tahun 2022

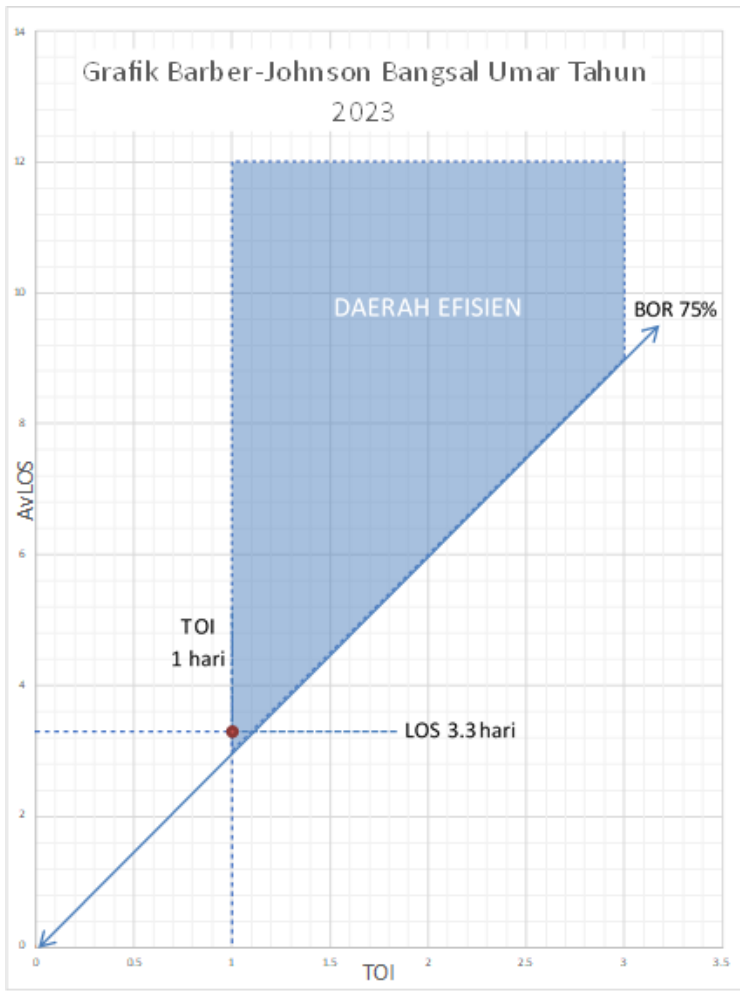

Gambar 5. Grafik Barber-Johnson Bangsal Umar pada Tahun 2023 
Pada Gambar 4, ditunjukkan hasil grafik Barber-Johnson sesuai dengan nilai indikator yang didapatkan untuk tahun 2022. Dari gambar tersebut dapat dilihat bahwa titik pertemuan antar indikator jatuh di daerah efisien, sehingga dapat dikatakan bahwa hasil prediksi jumlah tempat tidur pada bangsal Umar untuk tahun 2022 adalah efisien sesuai dengan standar Barber-Johnson.

Sementara hasil prediksi jumlah tempat tidur untuk tahun 2023 pada bangsal Umar adalah 22 tempat tidur. Dari hasil tersebut kemudian dapat dibuat grafik Barber-Johnson dengan menggunakan hasil perhitungan nilai LOS dan TOI yaitu sebagai berikut: $\operatorname{LOS}=6051$ $/ 1817=3.3$ hari, dan TOI $=(22-16.58) \times 365 /$ $1817=1$ hari. Grafik Barber-Johnson untuk tahun 2023 pada bangsal Umar dapat dilihat pada Gambar 5. Pada gambar tersebut dapat terlihat bahwa hasil pertemuan nilai-nilai indikator berada di daerah efisien, sehingga dapat disimpulkan bahwa untuk tahun 2023 bangsal Umar diprediksi dapat mencapai efisiensi penggunaan tempat tidur.

Dari hasil prediksi dan evaluasi menggunakan teknik data mining random forest (RF) dan Statistik Barber-Johnson, dapat diketahui bahwa efisiensi penggunaan tempat tidur di bangsal Umar, RSI Kendal, Jawa Tengah untuk tahun 2021 hingga 2023 diprediksi tercapai dan sesuai dengan standar indikator Barber-Johnson. Penggunaan teknik random forest juga menjadi alternatif lain dalam proses prediksi khususnya dalam kasus data time series, dimana pada penelitian ini variabel yang diprediksi adalah jumlah hari perawatan dan jumlah pasien keluar hidup dan mati.

\section{SIMPULAN}

Penelitian mengenai prediksi kebutuhan tempat tidur dengan studi kasus di bangsal Umar, RSI Kendal, Jawa Tengah dengan memanfaatkan teknik data mining random forest (RF) dan standar Barber-Johnson telah dilakukan. Hasil penelitian didapatkan dengan memanfaatkan data rekapitulasi dari 5 tahun sebelumnya yaitu antara 2015 hingga 2020. Variabel yang digunakan dalam penelitian ini adalah jumlah hari perawatan (HP), jumlah pasien keluar hidup dan mati, dan jumlah tempat tidur tersedia. Dari hasil pengolahan data dengan mengimplementasikan teknik random forest, didapatkan hasil prediksi hari perawatan dan jumlah pasien keluar hidup dan mati. Dari hasil tersebut kemudian dilakukan perhitungan statistik berdasarkan standar Barber-johnson untuk mengetahui jumlah tempat tidur untuk tahun 2021 hingga 2023, dimana pada bangsal Umar diprediksi memiliki 20 hingga 22 tempat tidur. Evaluasi terhadap tingkat efisiensi penggunaan tempat tidur di bangsal Umar dilakukan dengan memanfaatkan grafik BarberJohnson. Dari grafik yang dihasilkan, dapat disimpulkan bahwa hasil prediksi jumlah tempat tidur mampu mencapai tingkat efisien. Hal ini disebabkan karena pada grafik Barber-Johnson bangsal Umar untuk tahun 2021 hingga 2023 titik pertemuan indikator jatuh tepat berada di daerah efisien.

\section{DAFTAR PUSTAKA}

Anisah, J. (2021). Analisis sistem informasi akuntansi (SIA) pendapatan rawat inap kamar VIP RSU Bunda Tamrin Medan. Kumpulan Karya Ilmiah Mahasiswa Fakultas Sosial Sains, 2(02).

Defiyanti, R. S. P., Setiatin, S., \& Susanto, A. (2021). Analisis Trend Dan Grafik Barber Johnson Pada Efisiensi Tempat Tidur Di Rumah Sakit X Kota Bandung. Jurnal Ilmiah Perekam Dan Informasi Kesehatan Imelda (JIPIKI), 6(2), 119-130.

Diwani, M. E., \& Fahmi, M. A. (2020). Prediksi Kebutuhan Tempat Tidur Ruang Rawat Inap Kelas 1 Dan Kelas 2 di Rumah Sakit Gatoel Mojokerto Tahun 2020-2024. Jurnal Penelitian Kesehatan SUARA FORIKES (Journal of Health Research Forikes Voice), 11, 159-163.

Fahrudin, T. M. (2021). Cluster Analysis of Hospital Inpatient Service Efficiency Based on BOR, BTO, TOI, AvLOS Indicators using Agglomerative Hierarchical Clustering. Telematika: Jurnal Informatika Dan Teknologi Informasi, 18(2), 194-210.

Herawaty, A. S. (2021). Analisis Efisiensi Pelayanan Rawat Inap di Rs Ibnu Sina Makassar Tahun 2016, 2017, dan 2018 
(Melalui Pendekatan Barber-Johnson). MPPKI (Media Publikasi Promosi Kesehatan Indonesia): The Indonesian Journal of Health Promotion, 4(2), 121127.

Li, C., Liao, C., Meng, X., Chen, H., Chen, W., Wei, B., \& Zhu, P. (2021). Effective analysis of inpatient satisfaction: the random forest algorithm. Patient Preference and Adherence, 15, 691.

Limirang, R. S., \& Bachtiar, A. (2021). Perencanaan Strategi Pemasaran Dalam Upaya Peningkatan Kunjungan Pasien Poliklinik Gigi Rumah Sakit Satya Negara. An-Nadaa: Jurnal Kesehatan Masyarakat, 8(1), 34-47.

Nisa Srimayarti, B., Leonard, D., \& Zhuhriano Yasli, D. (2021). Determinants of Health Service Efficiency in Hospi-tal: A Systematic Review. International Journal of Engineering, Science and Information Technology, 1(3), 87-91. https://doi.org/10.52088/ijesty.v1i3.115

Nugraheni, S. W., \& Ruslinawati, Y. (2016). INJAUAN KELENGKAPAN DOKUMEN REKAM MEDIS PASIEN RAWAT INAP PENYAKIT TYPHOID FEVER DI RSUD BANYUDONO BOYOLALI TAHUN 2012. Jurnal INFOKES Universitas Duta Bangsa Surakarta, 3(3).

PRISUSANTI, R. D., \& EFENDI, A. (2021). Statistik Fasilitas Layanan kesehatan. Literasi Nusantara.

Ruyssinck, J., van der Herten, J., Houthooft, R., Ongenae, F., Couckuyt, I., Gadeyne, B., ... Dhaene, T. (2016). Random Survival Forests for Predicting the Bed Occupancy in the Intensive Care Unit. Computational and Mathematical Methods in Medicine, 2016, 1-7. https://doi.org/10.1155/2016/7087053

Seha, H. N., Nugroho, F. R. P., \& Harno, H. (2021). EFISIENSI INDIKATOR RAWAT INAP RS RAJAWALI CITRA TAHUN 2019. PROSIDING DISKUSI ILMIAH" Inovasi Dan Teknologi Informasi Untuk Mendukung Kinerja PMIK Dalam
Masa Pandemi Covid 19".

Sidiq, R., \& Afrina, R. (2017). KAJIAN EFISIENSI PELAYANAN RUMAH SAKIT. Idea Nursing Journal, 8(1), 2934. https://doi.org/10.52199/inj.v8i1.8700

Silvana, M., Akbar, R., \& others. (2017). Pengembangan Model Business Intelligence Manajemen Rumah Sakit untuk Peningkatan Mutu Pelayanan (Studi Kasus: Semen Padang Hospital). JEPIN (Jurnal Edukasi Dan Penelitian Informatika), 3(2), 124-133.

Utami, S. T., Azizah, V. H., \& Setiatin, S. (2021). Indikator Rawat Inap Pada Masa Pandemi COVID-19 di RSI Assyifa Sukabumi. Cerdika: Jurnal Ilmiah Indonesia, 1(9), 1227-1239. 